\title{
OPEN Hatching phenology is lagging behind an advancing snowmelt pattern in a high-alpine bird
}

\author{
Christian Schano ${ }^{1,2 \varpi}$, Carole Niffenegger ${ }^{1}$, Tobias Jonas $^{3}$ \& Fränzi Korner-Nievergelt ${ }^{1}$
}

To track peaks in resource abundance, temperate-zone animals use predictive environmental cues to rear their offspring when conditions are most favourable. However, climate change threatens the reliability of such cues when an animal and its resource respond differently to a changing environment. This is especially problematic in alpine environments, where climate warming exceeds the Holarctic trend and may thus lead to rapid asynchrony between peaks in resource abundance and periods of increased resource requirements such as reproductive period of high-alpine specialists. We therefore investigated interannual variation and long-term trends in the breeding phenology of a highalpine specialist, the white-winged snowfinch, Montifringilla nivalis, using a 20-year dataset from Switzerland. We found that two thirds of broods hatched during snowmelt. Hatching dates positively correlated with April and May precipitation, but changes in mean hatching dates did not coincide with earlier snowmelt in recent years. Our results offer a potential explanation for recently observed population declines already recognisable at lower elevations. We discuss non-adaptive phenotypic plasticity as a potential cause for the asynchrony between changes in snowmelt and hatching dates of snowfinches, but the underlying causes are subject to further research.

To maximise reproductive success, animals need to rear their offspring when conditions are most favourable ${ }^{1}$. Many species utilize seasonally fluctuating food sources and thus need to time their reproduction to often relatively short periods of optimal conditions to avoid severe fitness consequences ${ }^{2}$. In birds, timing of reproduction is further complicated by the fact that non-tropical species regress their gonads outside of the reproductive season $^{3}$. They thus need to induce gonadal growth ahead of optimal conditions to reproduce and lay eggs ${ }^{4,5}$.

While photoperiod often serves as a predominant, proximate cue to induce gonadal growth and the onset of breeding $^{3-6}$, the precise timing of egg-laying and hatching will depend on local environmental conditions ${ }^{7}$. Birds therefore use further environmental cues to better predict the nesting season in advance ${ }^{8-10}$. However, the reliability of such cues may be impaired by climate change i.e., when cue and food source respond differently to the changing environment ${ }^{11,12}$. Climate change may therefore especially affect ecological specialists with narrow thermal niches and ephemeral food sources ${ }^{13,14}$.

As such, arctic-alpine habitats and their usually cold-adapted residents experience strong seasonality, predominantly determined by low temperatures ${ }^{15}$ which then cause prolonged periods of snow cover ${ }^{16}$ and short vegetation periods ${ }^{17}$. Arctic-alpine habitats currently experience broad landscape change ${ }^{18}$, disproportionate warming $^{19-21}$, shifts in seasonal, and elevational precipitation ${ }^{22,23}$, an increase of extreme weather events ${ }^{24}$ and changing snow cover durations ${ }^{25}$. As such, the strong seasonality of temperate high elevation habitats and differences in response to climate change between trophic levels thus constantly challenge arctic-alpine bird species ${ }^{26}$. Invertebrate availability quickly increases after snowmelt initiation and arctic and alpine species benefit from timing their broods so that chicks grow during peak invertebrate availability ${ }^{27-29}$. Although the relationship between nesting and snowmelt is evident for some arctic waders ${ }^{30}$ and passerines ${ }^{31}$, comparatively few studies focus on the role of snowmelt on the breeding phenology in alpine bird species ${ }^{32,33}$.

We therefore studied the role of snowmelt and other possible environmental cues on the breeding phenology of a high-alpine specialist, the white-winged snowfinch, Montifringilla nivalis (henceforth snowfinch). To do so, we analysed a data set on snowfinch hatching spanning 20 years to investigate (1) the proportion of broods hatching during snowmelt, (2) long-term changes of hatching dates and (3between-year variability of hatching dates as a function of environmental predictors. Snowfinches predominantly rear their offspring on larval tipulids whose availability strongly correlate with snow cover ${ }^{34}$. Snowfinches should thus benefit from breeding

${ }^{1}$ Swiss Ornithological Institute, 6204 Sempach, Switzerland. ${ }^{2}$ Department of Evolutionary Biology and Environmental Studies, University of Zurich, 8057 Zurich, Switzerland. ${ }^{3}$ Snow Hydrology, WSL Institute for Snow and Avalanche Research SLF, 7260 Davos Dorf, Switzerland. ${ }^{\varpi}$ email: christian.schano@vogelwarte.ch 
nest building

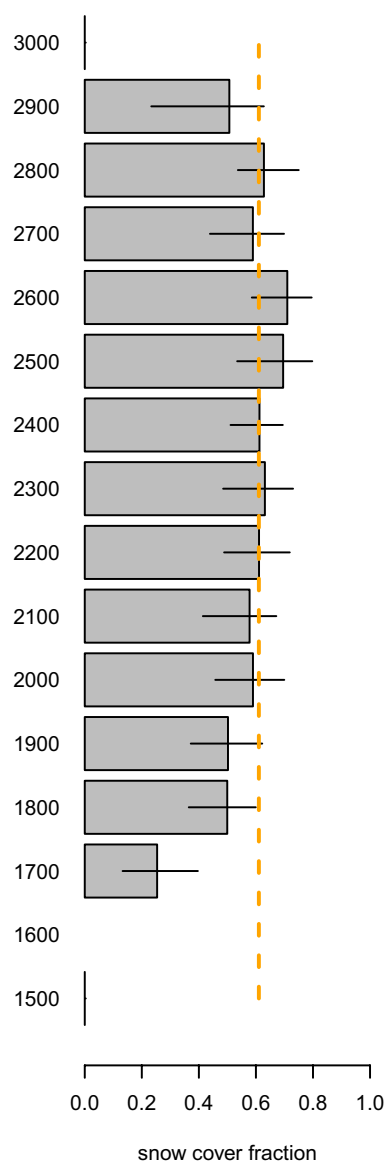

egg laying
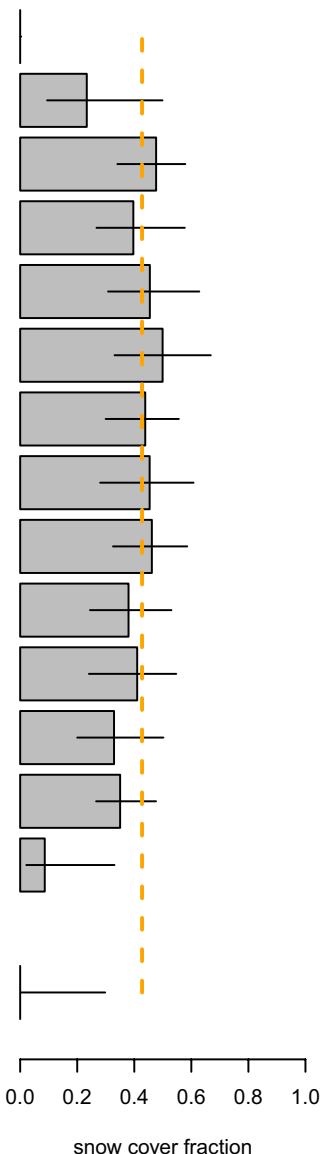

hatching

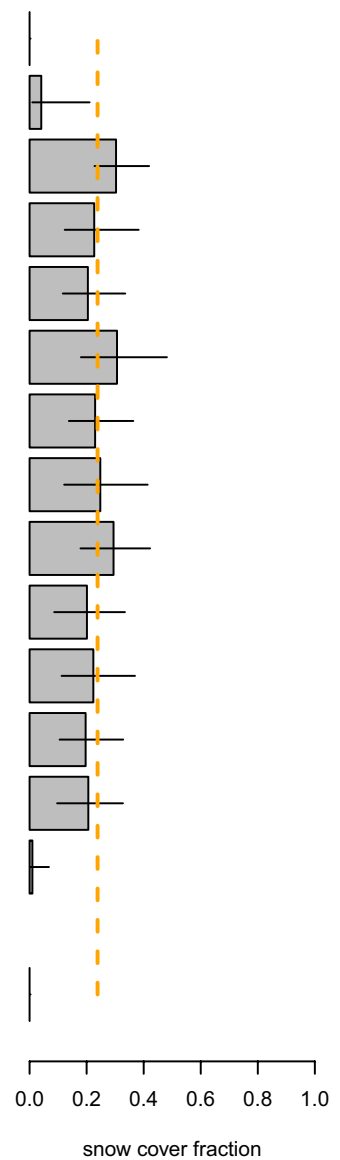

Figure 1. Mean snow cover fraction per elevation during nest building, egg laying and hatching. Error bars range from average earliest to average latest possible dates per event, orange lines (dotted) indicate mean snow cover fraction per event.

once the snow starts to melt, and we would expect a large proportion of broods to hatch during snowmelt and the average hatching date to advance in unison with a potential advance in snowmelt timing. We thus expected that hatching dates (a) advance with higher temperatures, even after correcting for snow condition and elevation because warm temperatures foster gonadal development, (b) delay with increased precipitation, because it compromises pre-breeding conditions, (c) advance with earlier snowmelt initiation independent of temperature and elevation, because the ocurrence of snow-free patches may be used as a cue to anticipate the timing of the peak food availability during snowmelt, and (d) delay after harsh winters, because adults may be in low body condition after more demanding winters.

\section{Results}

Breeding phenology in relation to snow cover fraction. On avagerage, snowfinches built nests when snow cover fraction was $61 \%$ (range: $48-71 \%$ ), layed eggs at around $43 \%$ (range: $28-57 \%$ ) and hatched at $24 \%$ (range: 13-38\%) based on 1135 broods and an annual mean of 57 (SD \pm 42 ) broods (Fig. 1). Only a minority of 7.11\% (range: $0.53-17.78 \%$ ) of snowfinches built nests before meltstart, and $1.07 \%$ (range: $0.36-3.91 \%$ ) layed eggs before meltstart. Nesting after the snow had melted completely was also rare: 9.6\% (range: 4.09-29.78\%) of nests and 19.64\% (range: 11.02-32.27\%) of egg laying were initiated after meltend. Thus, most snowfinches built nests, layed eggs and eggs hatched during the snowmelt, which, on average, lasted for 70 days (SD \pm 16 days) in $1 \times 1 \mathrm{~km}$ grid cells with snowfinch observations. Nearly two thirds, $64.22 \%$ (range: $46.87-76.48 \%$ ) also hatched during the snowmelt. The overall mean hatching date was June 24 th $(\mathrm{SD} \pm 17$ days), but annual average hatching dates ranged from June 16th ( $\mathrm{SD} \pm 15$ days) in 2017 to July 4 th ( $\mathrm{SD} \pm 11$ days) in 2013. At the elevational centre of their distribution, snowfinches bred at higher snow cover compared to broods at the edges of their elevational distribution. 

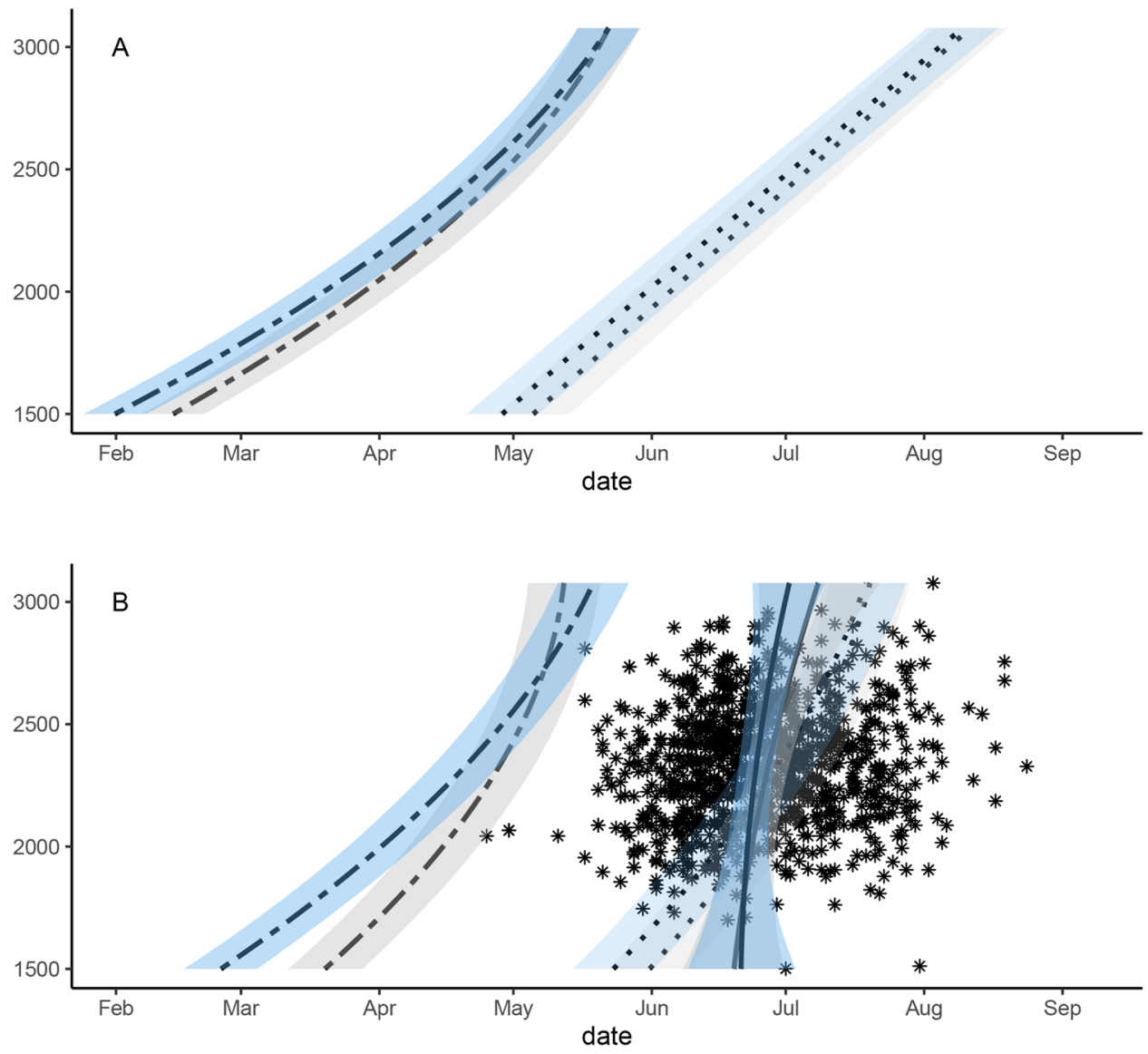

Figure 2. Mean dates for snowmelt initiation (twodash), snowmelt completion (dotted) and snowfinch hatching dates (solid) along the elevational gradient for 1999 (grey) and 2018 (blue), based on all snowfinch data with snowmelt estimated based on a complete dataset of Swiss kilometre grid cells between 1500 and $3100 \mathrm{~m}$ (A) and those with snowfinch observations (B). Shaded areas represent 95\% Bayesian compatibility intervals.

Long-term changes in snowmelt and hatching phenology. Although mean meltstart advanced from April 11th (CI: April 4th-18th) in 1999 to April 5th (CI: March 29th-April 11th) in 2018, snowfinches did not advance hatching date at elevations below $2000 \mathrm{~m}$. However, average hatching date was earlier at high elevations even though snowmelt delayed. Further, snowfinches bred in $1 \times 1 \mathrm{~km}$ grid cells with significantly later snowmelt compared to grid cells without snowfinch observations (Fig. 2A,B). In 1999, the estimated hatching date was 65 (range: 50-80) days after meltstart but in 2018, it had prolonged to 71 (range: 60-85) days after meltstart. Relative to meltstart, snowfinches generally bred later at lower elevations compared to higher elevations. This difference became more pronounced towards the end of the study period. Changes in average hatching dates were largest at high elevations, whereas they were smallest below $2200 \mathrm{~m}$ asl with mean changes of less than a day per decade.

Spatiotemporal pattern in hatching date. Given observers would be active at the same dates, mean hatching dates at an elevation of $2450 \mathrm{~m}$ asl varied between biogeographic regions, being earliest in the Western Alps (June 19th, CI June 17th-June 22nd) and latest in the Southern Alps (June 26th, CI June 23rd-June 29th) (Table 1). The conditional mean hatching dates in the Eastern Alps (June 24th, CI June 22nd-June 26th) and the Northern Alps (June 25th, CI June 23rd-June 27th) were more similar to the Southern Alps. We found a clear positive correlation between mean hatching date and observer date (2.06, CI: 1.86-3.21 days). Average hatching dates advanced over the years (Fig. 3A), more strongly so at higher elevations, although CIs for the coefficents of elevation and year were broad (Fig. 3B).

Hatching date in relation to environmental variables. Precipitation showed a clear positive relationship with snowfinch hatching dates (1.14; CI: $0.001,2.28)$, thus suggesting a one-day delay in hatching date with $111 \mathrm{~mm}$ of additional precipitation between April and May (CI: 38.47, $672.64 \mathrm{~mm}$ ) (Fig. 4B). Partial correlations of all other environmental variables showed broad compatibility intervals indicating that these relationship are difficult to measure (Fig. 4A,C,D). 


\begin{tabular}{|c|c|c|c|c|c|}
\hline \multirow[b]{2}{*}{ Parameters } & \multicolumn{2}{|l|}{ Spatiotemporal model } & \multicolumn{2}{|l|}{ Environmental model } & \multirow{2}{*}{\begin{tabular}{|l} 
Raw data \\
SD
\end{tabular}} \\
\hline & $\beta$ (SE) standardised & $\beta(\mathrm{SE})$ unstandardised & $\beta$ (SE) standardised & $\beta(\mathrm{SE})$ unstandardised & \\
\hline Region [EA] & - & $175.29(1.06)$ & - & $175.50(1.03)$ & 15.73 days \\
\hline Region [NA] & - & $176.36(1.13)$ & - & $175.84(1.06)$ & 18.48 days \\
\hline Region [SA] & - & $177.57(1.53)$ & - & $176.90(1.49)$ & 16.13 days \\
\hline Region [WA] & - & $170.93(1.14)$ & - & $171.67(1.07)$ & 17.87 days \\
\hline \begin{tabular}{|l|} 
Elevation \\
\end{tabular} & $0.73(3.74)$ & $0.3(1.54) 100 \mathrm{~m}^{-1}$ & $-0.6(3.86)$ & $-0.25(1.59) 100 \mathrm{~m}^{-1}$ & $243.22 \mathrm{~m}$ \\
\hline Elevation $^{2}$ & $0.32(3.71)$ & $0.13(1.53) 100 \mathrm{~m}^{-1}$ & $0.92(3.76)$ & $0.38(1.55) 100 \mathrm{~m}^{-1}$ & - \\
\hline Mean observer day & $8.24(0.46)$ & $0.49(0.03)$ day $^{-1}$ & $8.17(0.46)$ & $0.48(0.03)$ day $^{-1}$ & 16.97 days \\
\hline Year & $-0.66(0.73)$ & $-1.33(1.48)$ decade $^{-1}$ & $-0.68(0.66)$ & $-1.38(1.33)$ decade $^{-1}$ & 4.94 years \\
\hline Elevation:year & $-0.06(0.44)$ & $\begin{array}{l}-0.05(0.37) 100 \mathrm{~m}^{-1} \\
\text { decade }^{-1}\end{array}$ & $-0.12(0.45)$ & $\begin{array}{l}-0.1(0.37) 100 \mathrm{~m}^{-1} \\
\text { decade }^{-1}\end{array}$ & \\
\hline Winter intensity & - & - & $-0.05(0.76)$ & $-0.05(0.76)$ & 1.18 (no unit) \\
\hline Precipitation & - & - & $1.14(0.58)$ & $0.9(0.46) 100 \mathrm{~mm}^{-1}$ & $2.08 \mathrm{~mm} /$ day \\
\hline Snowmelt initiation & - & - & $0.6(0.53)$ & $0.18(0.16)$ week $^{-1}$ & 22.83 days \\
\hline Temperature & - & - & $-1.05(1.03)$ & $-0.5(0.49){ }^{\circ} \mathrm{C}^{-1}$ & $2.11^{\circ} \mathrm{C}$ \\
\hline $\begin{array}{l}\text { Among-year standard } \\
\text { deviation }\end{array}$ & & 2.7 (CI: $1.5-4.4)$ & & 1.9 (CI: $0.3-3.7)$ & \\
\hline
\end{tabular}

Table 1. Standardised and unstandardised parameters for the spatiotemporal and environmental model including Bayesian compatibility intervals and standard deviations. Unstandardised parameters show change in hatching date per unit of the predictor. Winter intensity has no unit because it is measured as a principal component of temperature and precipitation.
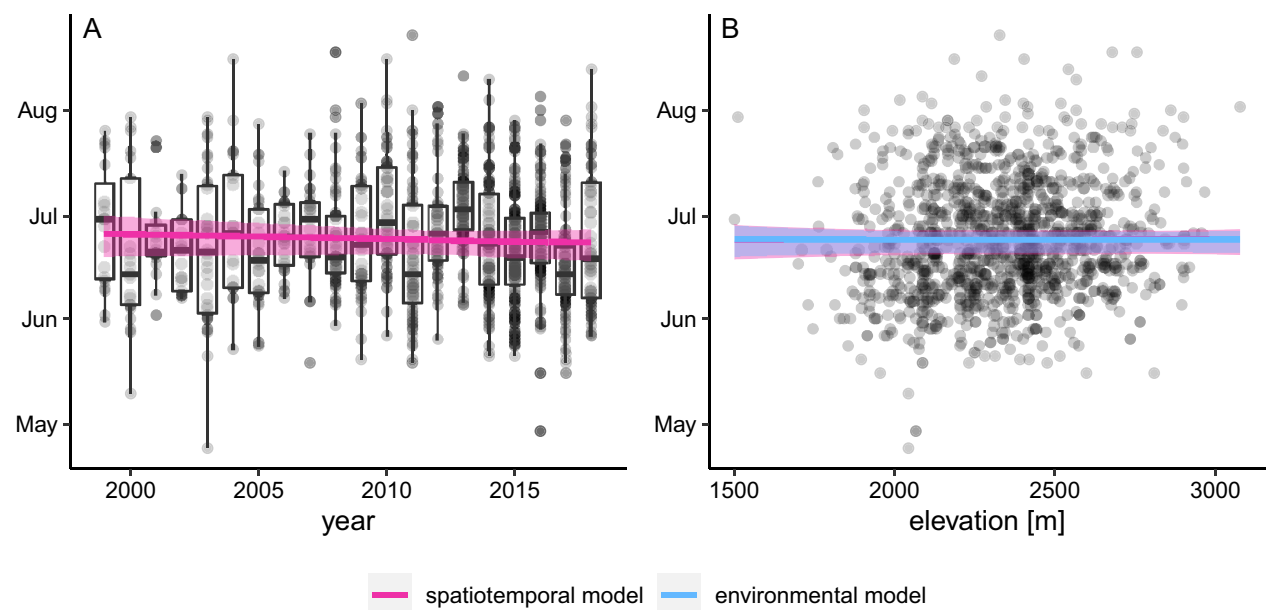

Figure 3. Hatching date of snowfinches in relation to year (A) and elevation (B) between 1999 and 2018. Lines represent regression lines of a model including spatiotemporal predictors (pink) and from a model also including environmental predictors (blue). Polygons show Bayesian 95\% compatibility intervals accordingly. In (A), we only show the regression line for the spatiotemporal model because the regression lines of the two models were essentially identical.

Observer bias. To assess observer phenology on the observed brood phenology, we investigated observer behaviour along the elevational gradient and snowmelt patterns. We compared spatiotemporal observer distribution with the distribution of hatching dates using bivariate normal kernel densities ${ }^{35}$ (Supplementary 1). Less than half the observers, $44.58 \%$, were present during snowmelt. Observers covered the entire breeding season and exceeded the $95 \%$ mass distribution of snowfinches both before and after the peak of the breeding season. Relative to snowmelt, $95 \%$ of observers entered data between 20 days before and 180 days after the snowmelt and thus covered snowfinch broods well, as these mostly hatched between 2 and 127 days after snowmelt.

\section{Discussion}

Breeding phenology in relation to snow cover fraction. Our results support the many former studies that showed how strongly the nesting timing of snowfinches are connected to snowmelt. Snow cover is an important modulator in ecological systems across mountain ranges and often affects breeding performance in alpine specialists ${ }^{32,36,37}$. Snowfinches may feed on arthropod fallout on snow patches but particularly forage for 

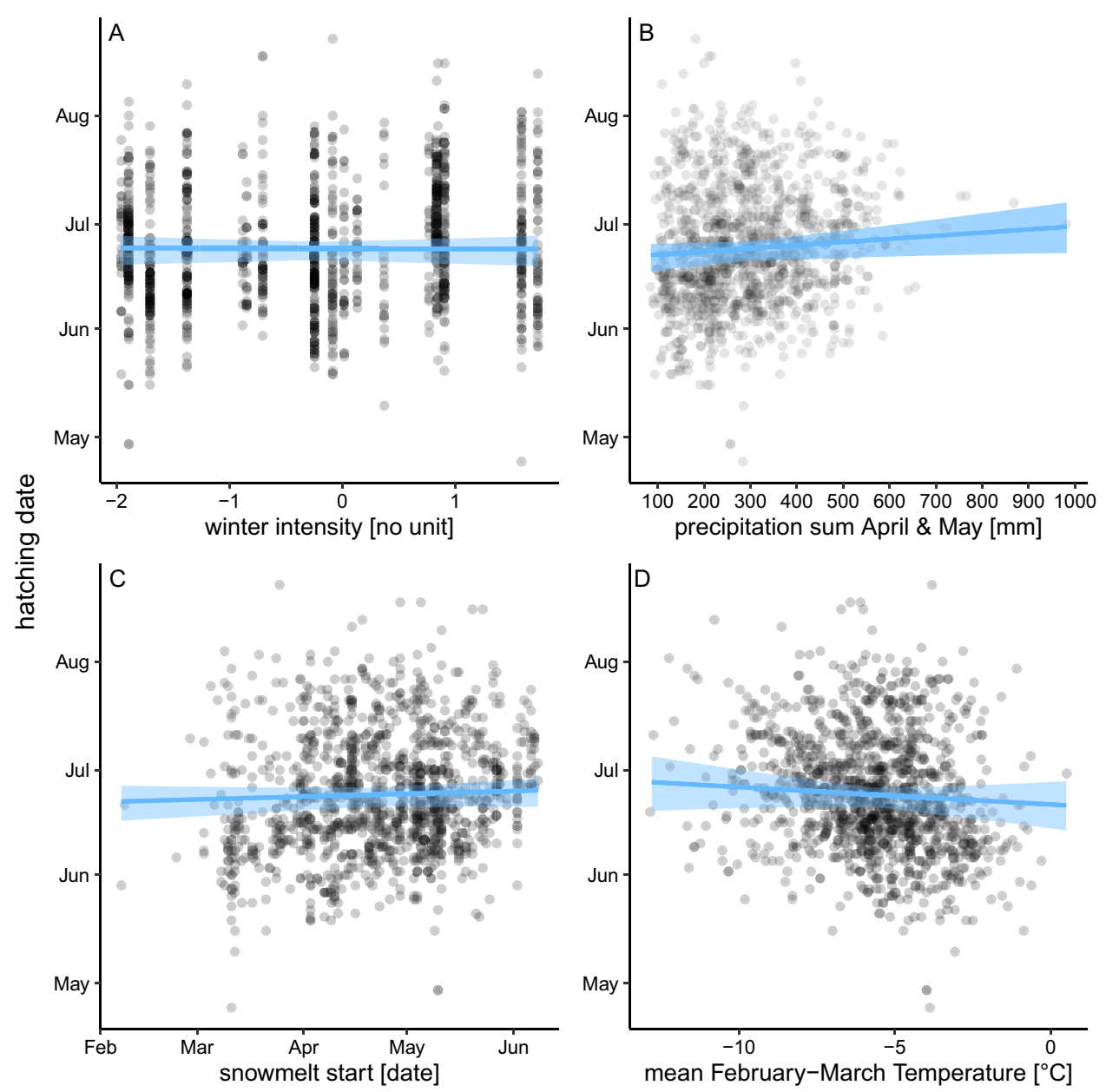

Figure 4. Hatching date of snowfinches in relation to partial effect sizes of winter intensity (A), precipitation (B), snowmelt initiation (C) and temperature (D) as estimated from a model including both spatiotemporal and environmental predictors. Blue polygons show Bayesian 95\% compatibility intervals.

larval arthropods, only accessible once the snow melts ${ }^{34,38,39}$. Snow cover may thus proximately predetermine laying and hatching dates, limited by the availability of nesting material or protein-rich prey for egg development and feeding offspring ${ }^{32}$. Our results suggest only a small fraction of laying events (range: $0.36-3.91 \%$ ) to occur before meltstart. Further, snowfinches lay eggs at about $43 \%$ and hatch at about $23 \%$ snow cover. They may thus particularly exploit early peaks in food abundance, specifically tipulid larvae, which emerge beneath melting snow and overproportionally contribute to early spring arthropod biomass ${ }^{29,34}$.

On average, two thirds of snowfinch broods hatched during the snowmelt period and the mean hatching date was around June 25th in 2011 for the Northern Alps, translating to an approximate laying date around June 12th at $2450 \mathrm{~m}$ asl. This is considerably later than reported by Heiniger in $1991^{40}$ for the Bernese Alps (Northern Alps) where he suggested snowfinches to lay eggs independent of temperature and the snow situation from the second half of May. However, Heiniger ${ }^{40}$ visited previously known, small-scale breeding sites and likely only included first broods. In contrast to Heiniger's method, we inferred hatching dates from the behaviour of adults. Therefore, broods that did not hatch are likely underrepresented in our data. Additionally, our method cannot distinguish between first and second broods, possibly resulting in later average hatching dates than Heiniger ${ }^{40}$ suggested.

Long-term changes in snowmelt and hatching phenology. Since the breeding and foraging behaviour of birds are ultimately determined by favourable physiological conditions and food availability ${ }^{41}$, we would expect hatching dates to change over time in proportion to environmental conditions that affect food abundance. However, we found average hatching date to be stable at low elevations, even though meltstart advanced considerably. In contrast, hatching slightly advanced at higher elevations although meltstart delayed over the course of two decades. Previous studies have shown that phenological shifts in larval arthropods correspond to long-term snowmelt patterns ${ }^{34,42}$. Therefore, non-parallel long-term changes in snowmelt and hatching date would suggest that there are drivers of change in mean hatching dates which are not synchronised with the timing of peaks in food abundance. We can think of three, not mutually exclusive explanations for heterogeneous shifts of snowfinch hatching dates along an elevational gradient. 
Firstly, an advance in average hatching date could be caused by a decrease in the proportion of multiple broods at the respective elevations. Snowfinches are facultatively double-brooded, but the proportion of double brooded pairs in snowfinches may be highly variable in space and time. Snowfinches may skip breeding in years with late snowmelt, whereas in other years they can breed twice ${ }^{40}$. In the French Pyrenees, $50 \%$ of the breeding pairs are double brooded ${ }^{43}$ and in the Abruzzi mountains, all pairs breed twice ${ }^{44}$. The proportion of second broods in our data is unknown, but it could have decreased over time either due to a reduced number of pairs producing second broods, or by a larger proportion of undetected abandoned or failed second broods. A decreasing proportion of second broods could probably also explain largely constant hatching dates at lower elevations, as a reduction of second broods may be associated with a delay of the first brood towards a peak in food availability when snowfinches were historically adapted to start the first brood well before the peak food availability to favor second broods ${ }^{45}$. However, average hatching date at low elevations was connected with strongly decreasing proportions of broods hatching during the snowmelt and thus, the peak food availability. Secondly, a constant average hatching date at low elevation could result from simultaneously advancing the first brood and increasing the proportion of second broods. However, because the proportion of broods hatching during snowmelt strongly decreased (see results) and we have no indication that the duration of the breeding season increased over the years (Supplementary 2), we can exclude that increasing proportions of second broods blur an advance in the observed average hatching date at elevations below $2000 \mathrm{~m}$. At higher elevations, a decreasing proportion of second broods likely explains the slight advance in average hatching date because it is unlikely that snowfinches start breeding earlier relative to snowmelt. Lastly, average hatching dates could simply not have changed over time, whereas snowmelt advanced at elevations below $2000 \mathrm{~m}$ across the study period. The increasing temporal lag between snowmelt and hatching date may have resulted in deteriorating breeding conditions, which may explain the observed population decline at low elevations ${ }^{46}$.

Environmental parameters influencing breeding phenology. We found considerable among-year variation in mean hatching dates, indicating that snowfinches use flexible cues to respond to variability in environmental conditions. Our results suggest spring precipitation (April-May) to be an important environmental factor that potentially serves as a modulator for breeding phenology $y^{47,48}$. Extreme weather events like heavy snowfall or extreme temperature decreases at the beginning of the breeding season can affect the breeding performance of arctic and alpine species drastically ${ }^{49}$.

April and May precipitation in snowfinch breeding habitat is largely comprised of snowfall and therefore strongly determines the conditions experienced during the courtship and brood initiation phase. Snowfinches may suffer from spontaneous snow onset by losing access to food resources or being forced to travel larger distances to provide offspring with food ${ }^{49}$. Spring precipitation may thus explain the rather large among-year variation in mean hatching dates, indicating that snowfinches use spring precipitation as an environmental cue to predict the onset of breeding.

For the other variables, snowmelt, temperature and winter intensity, uncertainty in the partial correlation coefficients were high. Our results regarding these variables therefore do not indicate strong partial correlations with the brood initiation of snowfinches but may still bear consequences for snowfinches and thus need further research.

Winter intensity could affect snowfinch breeding behaviour in two ways. On the one hand, harsh winters may delay breeding initiation or force snowfinches to skip breeding entirely ${ }^{40,50}$, therefore prioritising individual survival $^{51}$. On the other hand, snow-rich winters are associated with good thermal insolation, little soil frost and late meltend, resulting in warm soil temperatures after meltend. This may have a positive effect on larval tipulid abundance overwintering under the snow and could thus assure food supply for snowfinches to find once the snow melts. Further, spring temperature is a known modulator for critical phases during the breeding season, specifically so during gonadal recruitment and egg laying but may also hold negative effects on populations thereafter ${ }^{8}$.

Observer effect. Often, citizen science data is the only source of information available for specific biological measures. Hence, they are invaluable for the description of long-term trends and large-scale trends in populations $s^{52}$ or phenology $y^{53}$, especially in difficult terrain where monitoring data is still scarce ${ }^{54}$. However, citizen science data is often characterised by heterogeneous observer activity and, therefore, patterns in observer activity need to be separated from patterns in the biological measure of interest before conclusions can be drawn. We assessed observer influence on two different scales. First, we compared observer distribution against hatching date distribution in relation to elevation and date. We argue that, in comparison to hatching dates, observers were wider and more homogeneously distributed along these two axes, suggesting an underlying biological rather than an observational cause. Secondly, we accounted for observer bias by including mean observer day as a predictor in the models analysing hatching dates. Our results indicate a strong relationship between observer and hatching day, hence emphasising the importance of accounting for observer bias, especially in difficult alpine terrain.

Potential Implications of climate change on high-alpine specialists. We analysed a long-term dataset of a high-alpine bird specialist and found among-year variance in hatching dates, correlated with April and May precipitation. Among-year variability in hatching dates suggest breeding snowfinches to be able to adjust the timing of their broods to current environmental conditions, but a long-term trend in average hatching date did not coincide with a long-term trend in snowmelt phenology. Growing scientific evidence suggests $\operatorname{arctic}^{55}$ and alpine ${ }^{56}$ vertebrates to have comparatively low genetic diversity and adaptive phenotypic plasticity may only enable high-alpine specialists to cope with meteorological variation below certain thresholds ${ }^{50,57}$. 
Evidence for microevolutionary changes in breeding phenology ${ }^{57}$, especially in alpine birds, is still scarce and we thus highlight the importance of further research on the evolutionary adaptation in alpine specialists. Our results may suggest a mismatch between the broods and the time of assumed peak food availabiltiy at low elevations in the Alpine population of snowfinches. Potential carry-over effects of such a mismatch may affect later stages of life, including breeding success $s^{50}$ and parental survival ${ }^{41}$. This may explain why snowfinch populations exceedingly decline at elevations below $2000 \mathrm{~m}$ asl ${ }^{46}$ and is in line with findings on Pleistocene fossil records indicating that species were more prone to shift their distribution ranges rather than tracking climate change despite much more drastic warming ${ }^{26}$. Snow cover duration in the Swiss Alps has, below $2500 \mathrm{~m}$ asl and regardless of region or elevation, declined by an average of 8.9 days per decade since the 1970 s, mainly due to earlier snowmelt ${ }^{58}$. Under current climate change scenarios, hatching dates may thus further dissociate from snowmelt initiation at lower elevations and potentially have severe fitness effects on snowfinches. Although the specific mechanisms are still largely unclear, warming temperatures might threaten high-alpine bird species in several ways ${ }^{59}$. As such, snowfinches are specifically sensible to warming temperatures and physiological consequences like hyperthermia have previously been hypothesised as a potential cause of lower female survival ${ }^{60}$. Higher temperatures may alter plant composition, growth speed and drying of alpine meadows ${ }^{61}$ and thus decrease food availability for snowfinches, increasing energy expenditure of feeding adults. Additionally, current climate models suggest an increase in extreme weather events ${ }^{48,49}$, possibly exceeding the physiological thresholds of alpine specialists at some point. Our results suggest that precipitation at an early stage of the breeding season may affect breeding phenology. However, little is known about the effects of extreme weather events on later stages of the breeding season and subsequent consequences on breeding performance. However, such effects are likely to affect breeding phenology only in subsequent seasons and then be diluted by other factors and may thus be difficult to see in our type of data. We therefore highlight that further research on the mechanisms through which climate change affects reproductive fitness in snowfinches and other cold-adapted species is urgently required ${ }^{62}$.

\section{Material and methods}

Study species. Snowfinches inhabit alpine and subnival habitats across the Palearctic and are resident to all major alpine mountain ranges of Central and Southern Europe with its nominotypical subspecies ${ }^{63}$. Snowfinches breed above the treeline from about $1.800 \mathrm{~m}$ asl, most densely at around $2450 \mathrm{~m}$ asl ${ }^{46}$ and primarily form loose colonies that nest in rock crevices from mid-May but secondarily also breed on anthropogenic structures (houses, ski lift poles) or in nest boxes ${ }^{40,64}$. Adults mostly provide their offspring with tipulid larvae collected along snow patch margins, later also including adult tipulids and other insects collected next to snow patches but are granivorous during the non-breeding period ${ }^{40,65}$.

Bird data and data selection. We analysed a data set from the Swiss Alps spanning 20 years (Supplementary 3). The data set consisted of observations from an online database (https://www.ornitho.ch), population monitoring data (1999-2018) ${ }^{46}$, and own systematic brood monitoring data (2015-2018). Observers reported location, accuracy of location, date, number of individuals, and atlas codes (Supplementary 4) of a snowfinch sighting. Atlas codes indicate the birds' behaviour during the breeding season, e.g. "adults with food for young" or "adults entering a nest site" 46 . Based on these atlas codes and known durations for nest building, incubation ${ }^{40}$, nestling period ${ }^{64}$ and fledgling period (pers. obs. \& pers. comm Maria Delgado 2019), we calculated earliest, mean and latest possible hatching date per record (Supplementary 4), the distance between earliest and latest possible hatching date thus indicating hatching interval.

Observers might have differed in their habits to report the number of observed snowfinches. As multiple individuals per record either belonged to one or more broods, we discarded the reported number of individuals and thus treated each record as a single brood observation. To avoid bias caused by repeated observations of the same brood, we calculated the number of broods per $1 \times 1 \mathrm{~km}$ grid cell and year. We first identified the minimum number of broods by finding mutually exclusive records of calculated hatching intervals. Per interval defined by these mutually exclusive records, we then chose a single interval from all overlapping intervals at random. If a single observer recorded more than one distinguishable brood on a single day, we included these unambiguously identified broods. For $1 \times 1 \mathrm{~km}$ grid cells and years where we had systematic brood monitoring data available, we only included the latter data. This led to a total of 1135 recorded unique broods including 49 broods of precise hatching dates from the brood monitoring data and 1086 broods with hatching intervals from the citizen science data. Using the same method as for calculating hatching dates, we calculated nestling intervals and egg laying intervals.

Spatiotemporal data. Per brood, we linked the information provided by the observers with the according biogeographic region, the elevation and calculated average observer day per kilometer square. We then used biogeographic region, elevation, year and average observer day for the spatiotemporal analysis. We used biogeographic regions defined by the Swiss Federal Office for the Environment ${ }^{66}$ to account for general climatic differences among regions within the Alps. Due to low sample sizes, Southern Tessin and Southern Alps were combined to region "Southern Alps" and Northern Alps and Prealps were combined to "Northern Alps" (Supplementary 5). Elevational data with a resolution of $200 \times 200 \mathrm{~m}$ from the Swiss Federal Office for Topography (DHM25/200, swisstopo) was used. Because the nest location of broods was measured at different spatial accuracy, we computed both mean and standard deviation of elevation according to the reported precision of the nest location. We extracted precise elevation with a standard deviation of $0.5 \mathrm{~m}$ for all broods with known nests. For broods with a precision of up to $200 \mathrm{~m}$, we used elevation per respective $200 \times 200 \mathrm{~m}$ grid cell and calculated the standard deviation for the respective and all adjacent $200 \times 200 \mathrm{~m}$ grid cells. The resulting $600 \times 600 \mathrm{~m}$ cell corresponds to larger home range size of snowfinches rearing ${ }^{39}$. For records of lower resolution, we calculated 
the mean of all $200 \times 200 \mathrm{~m}$ grid cells in the respective $1 \times 1 \mathrm{~km}$ grid cell and their standard deviation. We further calculated the average observer day per $1 \times 1 \mathrm{~km}$ grid cell and year based on the number of persons who recorded bird observations from that grid cell per day between April 1st and August 31st.

Environmental data. Temperature and precipitation data were provided by the Swiss Federal Institute for Forest, Snow and Lanscape Research WSL (Supplementary 6). We spatially integrated daily mean temperature and precipitation aggregated to $1 \times 1 \mathrm{~km}$ grid cells based on a resolution of $100 \times 100 \mathrm{~m}^{67}$. We used a sliding window approach to identify the period with the highest Pearson's product-moment correlation coefficient between hatching dates and temperature or precipitation, respectively. We investigated 7 windows of lengths between 1 and 90 days from January 1st to May 15th, corresponding to the 2.5 percentile of calculated mean hatching dates based on all records for which calculated hatching dates existed. Final windows for analysis were then chosen according to the following criteria: (1) the 20 highest correlations per window needed to fall on consecutive days and (2) the maximal correlation coefficient of the chosen window needed to exceed that of all other windows matching criteria (1). Accordingly, we chose mean February-March temperatures and mean April-May precipitation for later analysis. To account for the spatial uncertainty in the observational data, we calculated standard deviation of all aggregated $100 \times 100 \mathrm{~m}$ grid cells per respective $1 \times 1 \mathrm{~km}$ grid cell and used the average standard deviation per chosen window and record in our analysis. Gridded snow cover fraction was derived from daily observations at about 320 Swiss snow monitoring stations, assimilated into a distributed snowcover model following Magnusson et al. ${ }^{68}$. Within this model, sub-grid snow cover fraction was calculated according to Helbig et al. ${ }^{69}$ on a resolution of $1 \times 1 \mathrm{~km}$. We then used daily snow cover fraction per $1 \times 1 \mathrm{~km}$ grid cell to to calculate snowmelt initiation (henceforth meltstart) and snowmelt completion (henceforth meltend). Meltstart was defined as the first day after maximal snow cover. Meltend was defined as the first day with minimal snow cover after snowmelt initiation. We defined winter intensity as the first principal component of annual mean winter temperatures of northern Switzerland above $1000 \mathrm{~m}$ asl between December and February (Swiss National Basic Climatological Network $\left.{ }^{70}\right)$ and mean total winter snow depth measured at Weissfluhjoch $\left(46^{\circ} 49^{\prime} 59.797^{\prime \prime} \mathrm{N}\right.$ $9^{\circ} 48^{\prime} 23.183^{\prime \prime}$, $2691 \mathrm{~m}$ asl, Federal Office of Meteorology and Climatology, Supplementary 6).

Statistical modelling. We first used linear mixed-effect models to model mean snowfinch hatching dates from all 1135 broods ranging from 1500 to $3077 \mathrm{~m}$ asl (Supplementary 7). We then modelled meltstart and meltend for all Swiss $1 \times 1 \mathrm{~km}$ grid cells at the same elevational range and for all $1 \times 1 \mathrm{~km}$ grid cells with snowfinch observations for a given year. All five models included elevation and year and additionally, a quadratic effect for elevation, an interaction term between elevation and year as fixed effects. In addition, we included year as a random effect to account for among-year variance that may be present additionally to the long-term trend. We used the function "lmer" in the lme4 package ${ }^{71}$ in the R statistical environment version 4.0.1 ${ }^{72}$. We used the function "sim" $"$ to directly simulate 10.000 values from the joint posterior distribution of the model parameters while assuming $\mathrm{p}(\beta) \propto 1$ as flat prior distributions for the coefficients and $\mathrm{p}(\sigma) \propto \frac{1}{\sigma}$ for the variance parameters.

To obtain a description of the spatio-temporal patterns in hatching dates and to relate hatching dates to environmental variables we used two hierarchical models. In both models, we corrected for average observer day and accounted for the uncertainties in hatching dates. Further, in these models, we accounted for the variance in environmental variables that may be due to different precisions of the nest location by assuming a normal distribution with the mean and standard deviation measured of the environmental variables measured at the spatial resolution corresponding to the precision of the nest site location (see above).

In observational studies like ours, correlations among explanatory variables cannot be avoided. We therefore included all explanatory variables expected to affect responses in our models to determine partial correlations. Although including correlated predictors reduces power, removing one of two correlating effects would measure the effect of both predictors in a single correlation coefficient, but this estimate is not unbiased, as it is confounded by the other predictor. Because such partial effects do not correspond to the correlation in the data, we fitted two different models. One, using spatiotemporal parameters trying to describe patterns in the data, and another including spatiotemporal and environmental parameters, aiming to describe the mechanisms leading to the pattern. Nonetheless, Pearson's correlation coefficients between predictors were below 0.6 except for the correlation between the linear and quadratic term for elevation $(r=0.998$, Supplementary 8$)$. Further, variance inflation factor tests on all predictors resulted in VIF-values being lower than 1.9, which are not problematic for the purpose of using models to describe the data, rather than to predict future hatching dates.

In the first model, we modelled hatching date as a function of biogeographic region, elevation, year and average observer day and included a quadratic term for elevation, an interaction term between elevation and year and a random year effect. We represented the hatching date per brood to be normally distributed with a mean equalling the mean hatching date and a standard deviation being a quarter of the hatching interval. Thus, we assume the true hatching date to fall within the hatching interval with a probability of $95 \%$. Also, we accounted for uncertainty of nest site location by assuming a normal distribution for the elevation per brood with the mean and standard deviation of the elevation measured at the spatial resolution corresponding to the precision of the nest site location (see above).

In a second model, otherwise identical to the first, we further included winter intensity, mean spring temperature around the nest, precipitation and snowmelt timing to assess how environmental variables are related with snowfinch hatching date. As for elevation, we accounted for uncertainty in temperature and precipitation by assuming normal distributions with means and standard deviations as described above. For both models, we used Hamiltonian Monte Carlo simulation as implemented in $\operatorname{Stan}^{74}$ via the interface $\operatorname{rstan}^{75}$ to fit the models to the data ${ }^{74}$. We centred and scaled all numeric variables to ease convergence of the model fitting algorithm and for making some of the effect sizes comparable among each other. For both models, we simulated six Markov chains 
of length 10.000, each with the second half used to describe the posterior distributions of the model parameters. Priors were chosen identically for both models. For the intercept, we used a normal distribution with a mean corresponding to the overall mean hatching date (June 24th), and a standard deviation of 50 days. Of this prior distribution, $95 \%$ of the mass falls within the breeding season between May and August which we thus consider non-informative. For the standardised model coefficients, we used normal distributions with a mean of zero and a standard deviation of five days for both models and consider these weakly-informative priors. Year effects were assumed to follow a normal distribution with mean of zero and standard deviation of one. The prior distribution for the variance parameter $(\sigma)$ was described by a half-Cauchy distribution with a lower boundary at zero and a standard deviation of 20 . The prior distribution for the among-year variance $\left(\sigma_{\text {year }}\right)$ is described, by a half-Cauchy distribution with a location parameter set to zero and a scale parameter set to five. To check for convergence of the model fitting algorithm, we assessed the metrics and diagnostic plots provided by the r-packages rstan ${ }^{75}$ and shinystan ${ }^{76}$. For both models, Monte Carlo standard errors were less than 5\%, R-hat values were below 1.01 and the number of effective samples was above 1500 for all parameters. To assess the goodness of fit of the models, we used visual posterior predictive checks which indicated the observed data for both models to be within the expected range of distributions. Spatial autocorrelation was examined based on the spatial distribution of the residuals and visualising the average semi-variance against distance classes ${ }^{77,78}$, but neither showed systematic patterns. To ensure the compatibility of the different data sets, we ran the analysis of both hierarchical models separately for the entire dataset and a dataset without the brood monitoring data. Due to the similarities of the citizen science data set and the monitoring data, we cannot think of any temporal patterns in the quality of data. All computations were conducted in a Bayesian framework using the statistical computing software $\mathrm{R}$ version 4.0.1 $1^{72}$. We reported our results by presenting the mean of the posterior distribution as the point estimate and the $2.5 \%$ and $97.5 \%$ quantiles as a $95 \%$ compatibility interval $(\mathrm{CI})^{79}$.

\section{Data availability}

The datasets generated and analysed during this study are available in the "vogelwarte.ch Open Repository And Archive" repository at https://doi.org/10.5281/zenodo.5464653.

Received: 25 June 2021; Accepted: 26 October 2021

Published online: 12 November 2021

\section{References}

1. Helm, B. et al. Annual rhythms that underlie phenology: Biological time-keeping meets environmental change. Proc. R. Soc. $B$ Biol. Sci. 280, 20130016 (2013).

2. Bradshaw, W. E. \& Holzapfel, C. M. Evolution of animal photoperiodism. Annu. Rev. Ecol. Evol. Syst. 38, 1-25 (2007).

3. Dawson, A. Control of the annual cycle in birds: Endocrine constraints and plasticity in response to ecological variability. Philos. Trans. R. Soc. B Biol. Sci. 363, 1621-1633 (2008).

4. Dawson, A., King, V. M., Bentley, G. E. \& Ball, G. F. Photoperiodic control of seasonality in birds. J. Biol. Rhythms 16, 365-380 (2001).

5. Wingfield, J. C. \& Kenagy, G. J. Natural regulation of reproductive cycles. Vertebr. Endocrinol. Fundam. Biomed. Implic. 4, 181-241 (1991).

6. Hahn, T. P., Pereyra, M. E., Sharbaugh, S. M. \& Bentley, G. E. Physiological responses to photoperiod in three cardueline finch species. Gen. Comp. Endocrinol. 137, 99-108 (2004).

7. Perfito, N., Meddle, S. L., Tramontin, A. D., Sharp, P. J. \& Wingfield, J. C. Seasonal gonadal recrudescence in song sparrows: Response to temperature cues. Gen. Comp. Endocrinol. 143, 121-128 (2005).

8. Shutt, J. D. et al. The environmental predictors of spatio-temporal variation in the breeding phenology of a passerine bird. Proc. R. Soc. B Biol. Sci. 286, 20190952 (2019).

9. Drake, A. \& Martin, K. Rainfall and nest site competition delay mountain bluebird and tree swallow breeding but do not impact productivity. Auk 137, 1-18 (2020).

10. Bison, M. et al. Best environmental predictors of breeding phenology differ with elevation in a common woodland bird species. Ecol. Evolut. https://doi.org/10.1002/ece3.6684 (2020).

11. McNamara, J. M., Barta, Z., Klaassen, M. \& Bauer, S. Cues and the optimal timing of activities under environmental changes. Ecol. Lett. 14, 1183-1190 (2011).

12. Thackeray, S. J. et al. Phenological sensitivity to climate across taxa and trophic levels. Nature 535, 241-245 (2016).

13. Moussus, J.-P., Clavel, J., Jiguet, F. \& Julliard, R. Which are the phenologically flexible species? A case study with common passerine birds. Oikos 120, 991-998 (2011).

14. Chamberlain, D. et al. The altitudinal frontier in avian climate impact research. Ibis 154, 205-209 (2012).

15. Wipf, S., Stoeckli, V. \& Bebi, P. Winter climate change in alpine tundra: Plant responses to changes in snow depth and snowmelt timing. Clim. Change 94, 105-121 (2009).

16. Jonas, T., Rixen, C., Sturm, M. \& Stoeckli, V. How alpine plant growth is linked to snow cover and climate variability. J. Geophys. Res. Biogeosci. 113, G03013 (2008).

17. Kudo, G. \& Hirao, A. S. Habitat-specific responses in the flowering phenology and seed set of alpine plants to climate variation: Implications for global-change impacts. Popul. Ecol. 48, 49-58 (2006).

18. Trant, A., Higgs, E. \& Starzomski, B. M. A century of high elevation ecosystem change in the Canadian Rocky Mountains. Sci. Rep. 10, $9698(2020)$.

19. Ceppi, P., Scherrer, S. C., Fischer, A. M. \& Appenzeller, C. Revisiting Swiss temperature trends 1959-2008. Int. J. Climatol. 32, 203-213 (2012).

20. Pepin, N. et al. Elevation-dependent warming in mountain regions of the world. Nat. Clim. Chang. 5, 424-430 (2015).

21. Rosenzweig, C. et al. Attributing physical and biological impacts to anthropogenic climate change. Nature 453, 353-357 (2008).

22. Brunetti, M. et al. Precipitation variability and changes in the greater Alpine region over the 1800-2003 period. J. Geophys. Res. Atmos. 111, D11107 (2006).

23. Napoli, A., Crespi, A., Ragone, F., Maugeri, M. \& Pasquero, C. Variability of orographic enhancement of precipitation in the Alpine region. Sci. Rep. 9, 13352 (2019).

24. Diffenbaugh, N. S., Scherer, M. \& Ashfaq, M. Response of snow-dependent hydrologic extremes to continued global warming. Nat. Clim. Chang. 3, 379-384 (2013). 
25. Beniston, M., Keller, F. \& Goyette, S. Snow pack in the Swiss Alps under changing climatic conditions: An empirical approach for climate impacts studies. Theoret. Appl. Climatol. 74, 19-31 (2003).

26. Parmesan, C. Ecological and evolutionary responses to recent climate change. Annu. Rev. Ecol. Evol. Syst. 37, 637-669 (2006).

27. Saalfeld, S. T. et al. Phenological mismatch in Arctic-breeding shorebirds: Impact of snowmelt and unpredictable weather conditions on food availability and chick growth. Ecol. Evol. 9, 6693-6707 (2019).

28. Tulp, I. \& Schekkerman, H. Has prey availability for arctic birds advanced with climate change? Hindcasting the abundance of tundra arthropods using weather and seasonal variation. Arctic 61, 48-60 (2008).

29. Leung, M.C.-Y. et al. Phenology of hatching and food in low Arctic passerines and shorebirds: Is there a mismatch?. Arctic Sci. 4, 538-556 (2018).

30. Grabowski, M. M., Doyle, F. I., Reid, D. G., Mossop, D. \& Talarico, D. Do Arctic-nesting birds respond to earlier snowmelt? A multi-species study in north Yukon, Canada. Polar Biol. 36, 1097-1105 (2013).

31. Liebezeit, J. R., Gurney, K. E. B., Budde, M., Zack, S. \& Ward, D. Phenological advancement in arctic bird species: Relative importance of snow melt and ecological factors. Polar Biol. 37, 1309-1320 (2014).

32. Hendricks, P. Spring snow conditions, laying date, and clutch size in an alpine population of American Pipits. J. Field Ornithol. 74, $423-429$ (2003).

33. Pereyra, M. E. Effects of snow-related environmental variation on breeding schedules and productivity of a high-altitude population of dusky flycatchers (Empidonax oberholseri). Auk 128, 746-758 (2011).

34. Resano-Mayor, J. et al. Snow cover phenology is the main driver of foraging habitat selection for a high-alpine passerine during breeding: implications for species persistence in the face of climate change. Biodivers. Conserv. 28, 2669-2685 (2019).

35. Venables, W. N. \& Ripley, B. D. Modern Applied Statistics with S (Springer, 2002).

36. Bears, H., Martin, K. \& White, G. C. Breeding in high-elevation habitat results in shift to slower life-history strategy within a single species. J. Anim. Ecol. 78, 365-375 (2009).

37. García-González, R., Aldezabal, A., Laskurain, N. A., Margalida, A. \& Novoa, C. Influence of snowmelt timing on the diet quality of pyrenean rock ptarmigan (Lagopus muta pyrenaica): Implications for reproductive success. PLoS ONE 11, e0148632 (2016).

38. Antor, R. J. Arthropod fallout on high alpine snow patches of the Central Pyrenees, northeastern Spain. Arct. Alp. Res. 26, 72-76 (1994)

39. Brambilla, M. et al. Foraging habitat selection by alpine white-winged snowfinches Montifringilla nivalis during the nestling rearing period. J. Ornithol. 158, 277-286 (2017).

40. Heiniger, P. H. Anpassungsstrategien des Schneefinken (Montifringilla nivalis) an die extremen Umweltbedingungen des Hochgebirges. Der Ornithol. Beobachter 88, 193-207 (1991).

41. MacDonald, E. C., Camfield, A. F., Jankowski, J. E. \& Martin, K. An alpine-breeding songbird can adjust dawn incubation rhythms to annual thermal regimes. Auk 131, 495-506 (2014).

42. Mortensen, L. O., Schmidt, N. M., Høye, T. T., Damgaard, C. \& Forchhammer, M. C. Analysis of trophic interactions reveals highly plastic response to climate change in a tri-trophic high-arctic ecosystem. Polar Biol. 39, 1467-1478 (2016).

43. Grangé, J. L. Biologie de la reproduction de la Niverolle alpine Montifringilla nivalis dans les Pyrénnées occidentales françaises. Nos Oiseaux 55, 67-82 (2008).

44. Strinella, E., Vianale, P., Pirrello, S. \& Artese, C. Biologia riproduttiva del Fringuello Alpino Montifringilla nivalis a Campo Imperatore nel Parco Nazionale del Gran Sasso e Monti della Laga (AQ). Alula 18, 95-100 (2011).

45. Visser, M. E. et al. Variable responses to large-scale climate change in European Parus populations. Proc. R. Soc. Lond. Ser. B Biol. Sci. 270, 367-372 (2003).

46. Knaus, P. et al. Schweizer Brutvogelatlas 2013-2016. Verbreitung und Bestandsentwicklung der Vögel in der Schweiz und im Fürstentum Liechtenstein. (Schweizerische Vogelwarte, 2018).

47. Basist, A., Bell, G. D. \& Meentemeyer, V. Statistical relationships between topography and precipitation patterns. J. Clim. 7, 1305-1315 (1994).

48. Hock, R. et al. High mountain areas. in IPCC Special Report on the Ocean and Cryosphere in a Changing Climate (eds. Pörtner, H. O. et al.). 131-202. (IPCC-Intergovernmental Panel on Climate Change, 2019).

49. Schmidt, N. M., Reneerkens, J., Christensen, J. H., Olesen, M. \& Roslin, T. An ecosystem-wide reproductive failure with more snow in the Arctic. PLOS Biol. 17, e3000392 (2019).

50. Martin, K. \& Wiebe, K. L. Coping mechanisms of alpine and arctic breeding birds: extreme weather and limitations to reproductive resilience. Integr. Comp. Biol. 44, 177-185 (2004).

51. Williams, C. T. et al. Seasonal reproductive tactics: Annual timing and the capital-to-income breeder continuum. Philos. Trans. R. Soc. B Biol. Sci. 372, 20160250 (2017).

52. Barlow, K. E. et al. Citizen science reveals trends in bat populations: The National Bat Monitoring Programme in Great Britain. Biol. Cons. 182, 14-26 (2015).

53. Strebel, N., Kéry, M., Schaub, M. \& Schmid, H. Studying phenology by flexible modelling of seasonal detectability peaks. Methods Ecol. Evol. 5, 483-490 (2014).

54. Maggini, R. et al. Are Swiss birds tracking climate change?: Detecting elevational shifts using response curve shapes. Ecol. Model. 222, 21-32 (2011).

55. Gilg, O. et al. Climate change and the ecology and evolution of Arctic vertebrates. Ann. N. Y. Acad. Sci. 1249, 166-190 (2012).

56. Gossmann, T. I. et al. Ice-age climate adaptations trap the alpine marmot in a state of low genetic diversity. Curr. Biol. 29, 1712-1720 (2019).

57. Charmantier, A. \& Gienapp, P. Climate change and timing of avian breeding and migration: Evolutionary versus plastic changes. Evol. Appl. 7, 15-28 (2014).

58. Klein, G., Vitasse, Y., Rixen, C., Marty, C. \& Rebetez, M. Shorter snow cover duration since 1970 in the Swiss Alps due to earlier snowmelt more than to later snow onset. Clim. Change 139, 637-649 (2016).

59. Scridel, D. et al. A review and meta-analysis of the effects of climate change on Holarctic mountain and upland bird populations. Ibis 160, 489-515 (2018)

60. Strinella, E., Scridel, D., Brambilla, M., Schano, C. \& Korner-Nievergelt, F. Potential sex-dependent effects of weather on apparent survival of a high-elevation specialist. Sci. Rep. 10, 8386 (2020).

61. Gottfried, M. et al. Continent-wide response of mountain vegetation to climate change. Nat. Clim. Chang. 2, 111-115 (2012).

62. Kharouba, H. M. \& Wolkovich, E. M. Disconnects between ecological theory and data in phenological mismatch research. Nat. Clim. Chang. 10, 406-415 (2020).

63. Summers-Smith, J. Handbook of the Birds of the World, Volume 14: Bush-Shrikes to Old World Sparrows. (2009).

64. Glutz von Blotzheim, U., Bauer, K. \& Bezzel, E. I: Passeridae. in Handbuch der Vögel Mitteleuropas. Vol. 12 (Akademische Verlagsgesellschaft, 1997).

65. Antor, R. J. The importance of arthropod fallout on snow patches for the foraging of high-alpine birds. J. Avian Biol. 26, 81-85 (1995).

66. Gonseth, Y., Wohlgemuth, T., Sansonnens, B. \& Buttler, A. Die Biogeographischen Regionen der Schweiz. Erläuterungen und Einteilungsstandard. Umwelt Materialien. Vol. 137 (2001).

67. Thornton, P. E., Running, S. W. \& White, M. A. Generating surfaces of daily meteorological variables over large regions of complex terrain. J. Hydrol. 190, 214-251 (1997). 
68. Magnusson, J., Gustafsson, D., Hüsler, F. \& Jonas, T. Assimilation of point SWE data into a distributed snow cover model comparing two contrasting methods. Water Resour. Res. 50, 7816-7835 (2014).

69. Helbig, N., van Herwijnen, A., Magnusson, J. \& Jonas, T. Fractional snow-covered area parameterization over complex topography. Hydrol. Earth Syst. Sci. 19, 1339-1351 (2015).

70. Begert, M. \& Frei, C. Long-term area-mean temperature series for Switzerland-Combining homogenized station data and high resolution grid data. Int. J. Climatol. 38, 2792-2807 (2018).

71. Bates, D., Mächler, M., Bolker, B. \& Walker, S. Fitting linear mixed-effects models using lme4. ArXiv e-prints 1406 (2015)

72. R Core Team. R: A Language and Environment for Statistical Computing. (2020).

73. Gelman, A. \& Su, Y.-S. Arm: Data analysis using regression and multilevel/hierarchical models. (2020).

74. Carpenter, B. et al. Stan: A probabilistic programming language. J. Stat. Softw. 76 (2017).

75. Stan Development Team. RStan: The R interface to Stan. (2020).

76. Gabry, J. shinystan: Interactive Visual and Numerical Diagnostics and Posterior Analysis for Bayesian Models. (2018)

77. Pebesma, E. J. Multivariable geostatistics in S: The gstat package. Comput. Geosci. 30, 683-691 (2004).

78. Pebesma, E. \& Bivand, R. S. S classes and methods for spatial data: the sp package. R News 5, 9-13 (2005).

79. Gelman, A. \& Greenland, S. Are confidence intervals better termed "uncertainty intervals"?. BMJ 366, I5381 (2019).

\section{Acknowledgements}

We sincerely thank the contributing observers for their invaluable reports without whom this publication would not have been possible. We thank Hans Schmid for preparing the snowfinch data and Dirk Schmatz for the temperature and precipitation data. Further, we thank Claire Pernollet for administering the nestling data and Gabriele Hilke Peter, Simeon Lisovski, Pietro Millanesi and Samuel Wechsler for their help in earlier stages of the analysis and Reto Burri for his comments on earlier manuscripts. The study was financially supported by the Yvonne Jacob foundation and by Swarovski.

\section{Author contributions}

C.S. designed the study, led the analysis and writing process, C.N. helped with interpreting the results and formulating the discussion, T.J. prepared the snow data, F.K. designed the study, supervised the analysis and writing process and all authors contributed to developing and improving the manuscript.

\section{Competing interests}

The authors declare no competing interests.

\section{Additional information}

Supplementary Information The online version contains supplementary material available at https://doi.org/ 10.1038/s41598-021-01497-8.

Correspondence and requests for materials should be addressed to C.S.

Reprints and permissions information is available at www.nature.com/reprints.

Publisher's note Springer Nature remains neutral with regard to jurisdictional claims in published maps and institutional affiliations.

(c) (i) Open Access This article is licensed under a Creative Commons Attribution 4.0 International License, which permits use, sharing, adaptation, distribution and reproduction in any medium or format, as long as you give appropriate credit to the original author(s) and the source, provide a link to the Creative Commons licence, and indicate if changes were made. The images or other third party material in this article are included in the article's Creative Commons licence, unless indicated otherwise in a credit line to the material. If material is not included in the article's Creative Commons licence and your intended use is not permitted by statutory regulation or exceeds the permitted use, you will need to obtain permission directly from the copyright holder. To view a copy of this licence, visit http://creativecommons.org/licenses/by/4.0/.

(c) The Author(s) 2021 